\title{
Hydraulic assessment of waste stabilization ponds: Comparison of computational fluid dynamics simulations against tracer data
}

\author{
Andres Alvarado ${ }^{1,2}$, Sreepriya Vedantam ${ }^{2}$, Galo Durazno ${ }^{3}$, Ingmar Nopens ${ }^{2}$ \\ ${ }^{1}$ Dirección de Investigación de la Universidad de Cuenca, Av. 12 de Abril s/n Cuenca, Ecuador \\ ${ }^{2}$ BIOMATH, Department of Applied Mathematics, Biometrics and Process Control, Ghent \\ University, Coupure Links 653, B-9000 Gent, Belgium \\ ${ }^{3}$ ETAPA, Empresa Pública Municipal de Telecomunicaciones, Agua Potable, Alcantarillado y \\ Saneamiento de Cuenca, Ecuador \\ Autor para correspondencia: andres.alvarado@ucuenca.edu.ec \\ Fecha de recepción: 3 de mayo de 2011 - Fecha de aceptación: 23 de junio de 2011
}

\begin{abstract}
The overall performance of a wastewater treatment plant is in addition to the effectiveness of the biokinetic processes controlled by the flow dynamics. A wide used technique to characterize the water flow dynamics is the use of tracers. At full-scale tracer experiments in wastewater treatment plants provide insufficient information to completely grasp the flow dynamics. Additionally results are often biased by uncontrolled external factors. As alternative, computational fluid dynamic (CFD) models for performance analysis of existing and the design of new wastewater treatment plants have been increasingly used over the last decade. The paper presents the results of a tracer experiment against the output of a CFD model with application to a 7 ha large maturation pond. The tracer study was conducted with the fluorescence dye Rhodamine WT using the stimulus response technique. The three dimensional CFD model was built considering a variable density distribution of spatial grids based on the specific characteristics of the system. For the unsteady flow simulations the turbulence model k- $\varepsilon$ was adopted. Residence time distribution (RTD) generated by both approaches were compared and showed fairly good agreement. The velocity and turbulence profiles of the CFD model were compared with experimental data confirming, although the high computational demand, the robustness of the used CFD model.
\end{abstract}

Keywords: Waste Stabilization Pond (WSP), tracer study, computational fluid dynamics (CFD).

\section{RESUMEN}

El rendimiento general de un sistema de tratamiento de aguas residuales depende, además de la efectividad de los procesos bio-cinemáticos, del desempeño hidrodinámico de los reactores que componen el sistema. En plantas de tratamiento de aguas residuales de gran escala, la información obtenida en pruebas de trazadores no es suficiente para un completo entendimiento de la hidrodinámica del sistema, además, estos experimentos son frecuentemente influenciados por factores externos no controlados. Como una alternativa, los modelos computacionales de flujo dinámico (CFD) han sido progresivamente utilizados en la última década como herramientas para el diseño y evaluación de sistemas de tratamiento de agua residual. El presente artículo detalla los resultados de una prueba de trazadores en comparación con los obtenidos con un modelo CFD de una laguna de maduración de gran escala ( 7 ha). La prueba de trazadores se realizó con la sustancia fluorescente Rodamina WT empleando la técnica estímulo-respuesta. El modelo CFD en tres dimensiones fue construido considerando una distribución variable de la densidad de elementos en la discretización espacial de acuerdo los característicos específicos del sistema. Para las simulaciones de flujo no estacionario fue utilizado el modelo de turbulencia $\mathrm{k}-\varepsilon$. Se realizó una evaluación de las dos alternativas por medio de curvas de distribución del tiempo de residencia (RTD) con un ajuste aceptable. Los perfiles de velocidad del modelo CFD fueron comparados con observaciones 
experimentales confirmando la gran capacidad de los modelos CFD para describir la hidráulica de un sistema lagunar; no obstante, con una gran demanda de recursos computacionales.

Palabras clave: Lagunas de estabilización, pruebas de trazadores, modelos computacionales de flujo dinámico (CFD).

\section{INTRODUCTION}

Waste Stabilization Ponds (WSPs) are low cost treatment plants of waste water in places where land is not a limiting factor. This technology is especially suited for (sub)tropical countries because of the abundance of sunlight and temperature, key factors in the treatment process (Mara et al., 1992). Moreover, WSP do not require major investment and maintenance, making it an attractive technology for developing countries (Dochain et al., 2003). The hydraulic regime of a pond determines the residence time the effluent water resides in the pond, affecting directly the overall performance of the WPS (Shilton et al., 2000). The analysis of the pond hydraulics is an essential step in the understanding of the effectiveness of the WSP, and this insight is needed as basis for the improvement of the plant operation.

Tracer studies are extensively applied for the determination of the transport, mixing, and diffusion properties of substances in water systems. Such studies basically involve the temporal and spatial monitoring of a tracer applied to the system. A variety of tracer substances are available, however in wastewater treatment plants fluorescent tracers are mostly used for the following reasons: (a) water soluble, (b) highly detectable at low concentrations, (c) fluorescent in a part of the spectrum not common for materials generally found in water, thus reducing the problem of background fluorescence, (d) harmless in low concentrations, (e) inexpensive, and (f) reasonably stable in a normal water environment (Valero and Mara, 2009).

The most commonly fluorescent tracer used in WSP is Rhodamine WT $\left(\mathrm{C}_{29} \mathrm{H}_{29} \mathrm{~N}_{2} \mathrm{O}_{5} \mathrm{ClNa}_{2}\right)$ which is considered non-biodegradable and non-absorbable by solids (Yanez, 1993). However, recent studies have shown that: (i) the fluorescent tracer has the tendency to be adsorbed, and (ii) the fluorescence intensity is depending from the temperature and conductivity of the effluent water in the WSP (Valero and Mara, 2009). Several studies in pond hydraulics has been conducted using the stimulus response technique in full-scale waste stabilization ponds, showing the usefulness of this technique for describing consistently the hydraulics of the pond systems (Domonte and Mara, 1987; Moreno, 1990; Torres et al., 1997; Torres et al., 1999; Shilton et al., 2000; Torres et al., 2000; Shilton et al., 2008). Unfortunately, the variable inflows and weather conditions directly affect the hydraulic and biogenetic behavior of the relative thin water layer in WPS, hindering the reproducibility of experiments in full-scale systems.

Mathematical models have been used successfully in wastewater treatment systems for both system analysis and optimization. Since the introduction of CFD models to predict the flow patterns in ponds by Wood et al. (1995), the interest in CFD modeling for waste stabilization ponds expanded rapidly, particularly in practical applications. A relative large number of studies describe the usefulness of CFD models as a tool for assessing the system hydraulics (Wood et al., 1998; Peterson et al., 2000; Salter et al., 2000; Shilton, 2000; Vega et al., 2003; Karteris et al., 2005; Sweeney et al., 2005), and the biochemical transformation and degradation processes (Shilton and Harrison, 2003; Sweeney et al., 2007). These authors also state that CFD models are very useful in the design of new plants and the definition of operation rules improving the effectiveness of existing plants. However, according to Shilton et al. (2008) little scientific evidence exist regarding the validation of CFD models on full-scale systems. The main constraint so far is the limitation of the computational resources.

In connection to previous, the objectives of the research reported in this paper are fourfold: (i) analysis of the flow characteristics of a maturation pond using a fluorescent tracer; (ii) validation of a 3D CFD model against the results of the tracer experiment; (iii) assessment of the hydraulic behavior 
of a full-scale maturation pond using the validated CFD model; and (iv) comparison of the residence time distribution curves derived from the tracer experiment and obtained with the CFD model.

\section{MATERIALS AND METHODS}

\subsection{The Waste Stabilization Pond System}

The Ucubamba WSP system, the largest wastewater facility in Ecuador, treats the domestic effluent of Cuenca city, having a population of 400.000 inhabitants (2010). Located at an altitude of $2560 \mathrm{~m}$ a.s.l. in the Andean mountain range, the WSP system is divided in two identical flow lines (Figure 1). Each line comprises an aerated lagoon (using mechanical floating aerators), a facultative lagoon and a maturation pond. The total surface of the WSP is 45 ha, and the theoretical hydraulic retention time is 12 days. The maturation pond M1 (Figure 1) where the study is performed is 7 ha large and 1,7 m deep. The inlet/outlet of the pond consists of a submerged pipe of $0,9 \mathrm{~m}$ diameter lying at the bottom of the pond and an overflow structure with a width of $10 \mathrm{~m}$. The location of both structures is shown in Figure 1. Several bathymetries were conducted revealing that in the maturation pond only a thin sludge layer is formed; less than $1 \%$ over the total pond volume with a maximum thickness of $10 \mathrm{~cm}$. On the basis of this the authors concluded that for the hydraulic analysis of the pond the influence of the sludge layer can be neglected. The WSP is in operation since 1999 and up to now no dredging of the sludge was conducted; however it might be relevant to do so in the near future. Despite the sludge accumulation, the treatment removal efficiencies (BOD 79\%; TSS 75\%; F.Colif. 99,92\%) only slightly decreased since 1999.

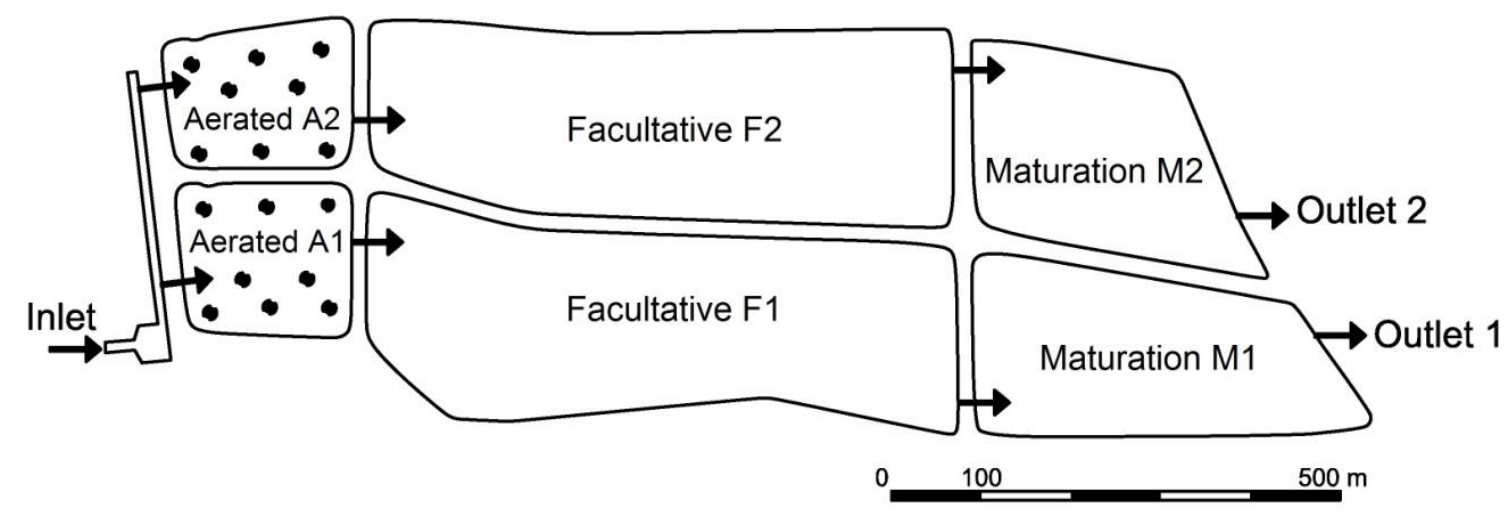

Figure 1. Ground plan of the Ucubamba waste stabilization pond (WSP), Cuenca, Ecuador.

\subsection{Tracer Study}

A tracer study was conducted in maturation pond M1 during the coldest and driest months of the year to prevent the impact of thermal stratification and to minimize the influence of rainfall on the variability of inflow effluent water. The tracer Rhodamine WT was mixed with pond water and added as a pulse in the channel upstream the inlet of the maturation pond in order to minimize the effect of thermal stratification. The fluorescence concentration in pond samples was measured using an Aquafluor $^{\mathrm{TM}}$ Fluorometer (http://www.turnerdesigns.com), a lightweight handheld instrument for fluorescense and turbidity measurements in-situ. The measuring device has a minimum detection limit of $0,4 \mathrm{ppb}$. Water samples were collected using an ISCO Automatic Sampler 6712 (http://www.isco.com). Sampling frequency was 15 minutes before the first peak of the tracer was observed, then gradually reduced to 60 minutes until $90 \%$ of the tracer was recovered, i.e. after 30 days. The samples were analyzed at the same temperature $\left(19^{\circ} \mathrm{C}\right)$, using when necessary a thermal bath. The influence of natural fluorescence of algal biomass was controlled by measuring the background fluorescence concentration during several hours before the start of the test (Valero and 
Mara, 2009). A detailed description of the experimental procedure can be found in (Espinoza and Rengel, 2009).

\subsection{CFD modeling}

3-D CFD simulations were performed on the maturation pond M1 (Figure 1) using the commercial software FLUENT v. 6.3 (ANSYS/FLUENT Inc., http://www.fluent.com). The finite volume method was selected dividing the computational domain into 75.000 quadratic grid elements. In order to account for the flow disturbances near the inlet and outlet structures and in the pond corners, where flow directions require accurate representation, a denser grid was applied in those regions of the maturation pond. Preliminary tests revealed that increasing the grid density in the remainder of the pond did not produce remarkable differences in the accuracy of the modeling results. Hence, in order to keep the computational cost at an acceptable level the grid size of 75.000 elements was maintained throughout all analyses, including the residence time distribution analysis. In the Cartesian coordinate system the three-dimensional mass and momentum equations can be described as:

$$
\begin{gathered}
\frac{\partial \rho}{\partial t}+\nabla \cdot(\rho \vec{v})=0 \\
\frac{\partial}{\partial t}(\rho \vec{v})+\nabla \cdot(\rho \vec{v} \vec{v})=-\nabla p+\nabla \cdot(\overline{\bar{\tau}})+\rho \vec{g} \\
\text { With, } \overline{\bar{\tau}}=\mu\left[\nabla \vec{v}+\nabla \vec{v}^{T}-\frac{2}{3} \nabla \cdot \vec{v} I\right]
\end{gathered}
$$

The scalar transport equation is written as:

$$
\frac{\partial \rho \phi_{k}}{\partial t}+\frac{\partial}{\partial x_{i}}\left(\rho v_{i} \phi_{k}-D_{k} \frac{\partial \phi_{k}}{\partial x_{i}}\right)=0
$$

Where, $\rho=$ density $\left[\mathrm{kg} \mathrm{m}^{-3}\right], \vec{v}=$ overall velocity vector $\left[\mathrm{m} \mathrm{s}^{-1}\right], p=$ static pressure $[\mathrm{Pa}], \overline{\bar{\tau}}=$ stress tensor $[\mathrm{Pa}], g=$ gravitational acceleration $\left[\mathrm{m} \mathrm{s}^{-2}\right], \mu=$ molecular viscosity $\left[\mathrm{kg} \mathrm{m}^{-1} \mathrm{~s}^{-1}\right], \mathrm{I}=$ unit tensor $[-], \phi_{k}=$ scalar [-], $D_{k}=$ diffusion coefficient $\left[\mathrm{m}^{2} \mathrm{~s}^{-1}\right]$.

The fluid in the pond is assumed to be incompressible and holding Newtonian fluid properties with a density of 998,2 $\mathrm{kg} \mathrm{m}^{-3}$ and a dynamic viscosity of $1,003 \mathrm{E}^{-3} \mathrm{~kg} \mathrm{~m}^{-1} \mathrm{~s}^{-1}$. These values are realistic considering the concentration of suspended solids in the pond, of the order of $30 \mathrm{mg} \mathrm{l}^{-1}$; a concentration not affecting fluid properties. The turbulence in the pond was modeled using the standard $\mathrm{k}-\varepsilon$ model. The $\mathrm{k}-\varepsilon$ model is the most commonly used of all turbulence models, and classified as a two equation model. The model equations are:

$$
\begin{gathered}
\frac{\partial}{\partial t}(\rho k)+\frac{\partial}{\partial x_{i}}\left(\rho k u_{i}\right)=\frac{\partial}{\partial x_{j}}\left[\left(\mu+\frac{\mu_{t}}{\sigma_{k}}\right) \frac{\partial k}{\partial x_{j}}\right]-\rho \overline{u_{\imath}^{\prime} u_{\jmath}^{\prime}} \frac{\partial u_{j}}{\partial x_{i}}-\rho \epsilon \\
\frac{\partial}{\partial t}(\rho \varepsilon)+\frac{\partial}{\partial x_{i}}\left(\rho \varepsilon u_{i}\right)=\frac{\partial}{\partial x_{j}}\left[\left(\mu+\frac{\mu_{t}}{\sigma_{\varepsilon}}\right) \frac{\partial \varepsilon}{\partial x_{j}}\right]-c_{1 \varepsilon} \frac{\varepsilon}{k}\left(\rho \overline{u_{\imath}^{\prime} u_{\jmath}^{\prime}}\right)-c_{2 \varepsilon} \rho \frac{\varepsilon^{2}}{k}
\end{gathered}
$$

Where, $k=$ kinetic energy $\left[\mathrm{m}^{2} \mathrm{~s}^{-2}\right], \varepsilon=$ turbulence dissipation rate $\left[\mathrm{m}^{2} \mathrm{~s}^{-3}\right], u_{i, j}=$ velocity components $\left[\mathrm{m} \mathrm{s}^{-1}\right], \sigma_{\kappa, \varepsilon}=$ turbulent Prandtl (Prt) numbers for $\mathrm{k}$ and $\varepsilon,\left(1,0\right.$ and 1,3 respectively) [-], $c_{l \varepsilon}$ and $c_{2 \varepsilon}=$ model constants (1,44 and 1,92 respectively) [-].

A transient inlet velocity profile was applied as an inlet boundary condition, which accordingly calculates the inlet turbulent boundary condition. The effect of wind and temperature gradients has been neglected. Additionally, in the flow field analysis vertical diffusion was neglected. The tracer residence time distribution (RTD) analysis (Levenspiel, 1999) was performed by imposing a transient 
simulation of tracer as a scalar on the velocity and turbulent fields obtained from the flow simulation. The dynamic advection of the tracer species having identical properties as the fluid in the primary phase has been considered for these simulations. The species transport model in FLUENT v. 6.3 was used for the determination of RTD. The tracer is injected at time $t=0$ for one time step giving a species mass fraction of 1 and then is reset to 0 for the second and following time steps. The RTD is obtained plotting the tracer concentration versus time at the pond outlet (Vedantam et al., 2006).

\subsection{Residence Time Distribution (RTD) Analysis}

The results of the CFD simulation were validated against the tracer study by means of the RTD analysis. This analysis provides directly two main parameters of the system: (i) the main residence time $(\bar{t})$, and the variance $\left(\sigma^{2}\right)$ which is a measure of the spread of the RTD curve. For discrete data both parameters are defined according to (Levenspiel, 1999) as follows:

$$
\begin{gathered}
\bar{t}=\frac{\sum t_{i} C_{i} \Delta t_{i}}{\sum C_{i} \Delta t_{i}} \\
\sigma^{2} \cong \frac{\sum\left(t_{i}-\bar{t}\right)^{2} C_{i} \Delta t_{i}}{\sum C_{i} \Delta t_{i}}=\frac{\sum t_{i}^{2} C_{i} \Delta t_{i}}{\sum C_{i} \Delta t_{i}}-\bar{t}^{2}
\end{gathered}
$$

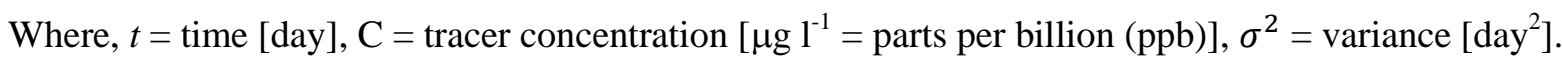

The variance can be expressed in its dimensionless form $\sigma_{\theta}^{2}$ and linked to the dispersion factor $d$, which characterizes the flow dispersion in the pond system using the following expression (Yanez, 1986):

$$
\sigma_{\theta}^{2}=\frac{\sigma^{2}}{\bar{t}^{2}}=2 d-2 d^{2}\left[\left(1-e^{-1 / d}\right)\right]
$$

Where, $\sigma_{\theta}^{2}=$ dimensionless variance [-], $\mathrm{d}=$ dispersion factor [-]. The parameters were derived using the experimental data and the CFD simulation results.

\section{RESULTS AND DISCUSSION}

\section{1. $\quad$ Tracer experiment observations}

In general terms, due to the vast size of the pond, the tracer movement through the water body was visible only for the first 30 minutes after the injection; this period, however, was sufficient to visualize that the bulk mass of tracer instead of spreading over the pond domain, it immediately moved to the right lateral side of the pond in direction to the right bottom corner (Figure 2). This behavior presumed a short circuit and a strong circular pattern of the tracer around the pond which is typical for this type of hydraulic systems without baffle structures (Shilton et al., 2008). In addition, a minor but visible amount of tracer remained in the corner closest to the inlet pipe, indicating a stagnant zone. As depicted in Figure 3, the first peak of the tracer appeared 2 hours after the pulse; a second peak was visible after 4 hours, respectively 2 hours later. After these two main peaks, the experiment showed no irregular changes in measurements.

\subsection{CFD model}

Figure 2 shows the contour and vector velocities in the middle depth horizontal surface of the pond obtained after 3 days of unsteady CFD simulation using the transient flow equations. In Figure 3, the highest velocities in the pond (in the range $0,2<v<1,12$ ) are entirely located in the none-colored zone, immediately after the inlet. Except for the region located around the inlet of the pond, which clearly behaves as a turbulent zone, the iso-surfaces clearly depict the vast majority of the pond 
(around $80 \%$ of the volume) behaving as a steady region with velocities below $0,05 \mathrm{~m} \mathrm{~s}^{-1}$. The velocity vectors show stagnant zones located in the upper-left and bottom-right corner of the pond and for the rest of the domain. The vectors have a clear dominant direction, illustrating the strong circular pattern of the flow around the pond. According to Figure 2 the flow mixing occurs in the region around the inlet. Despite the difference in depth location of inlet and outlet the variability of the velocity and turbulence horizontal profiles along the depth is minimal. The latter observation permits further simplification of the model, neglecting the vertical diffusion. It is stressed that no meteorological boundary was accounted for in the model.

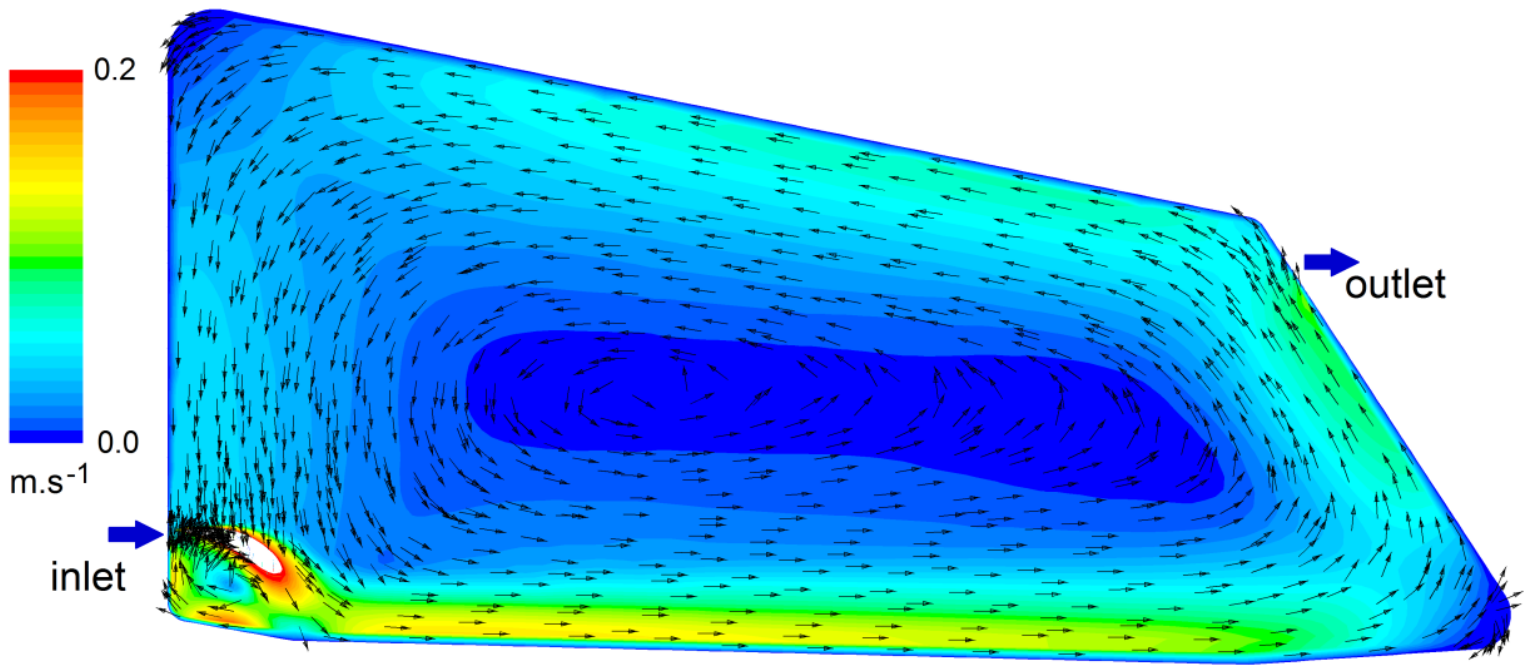

Figure 2. Velocity vector plot and contour plot of velocity magnitude in the maturation pond M1after 3 days of simulation.
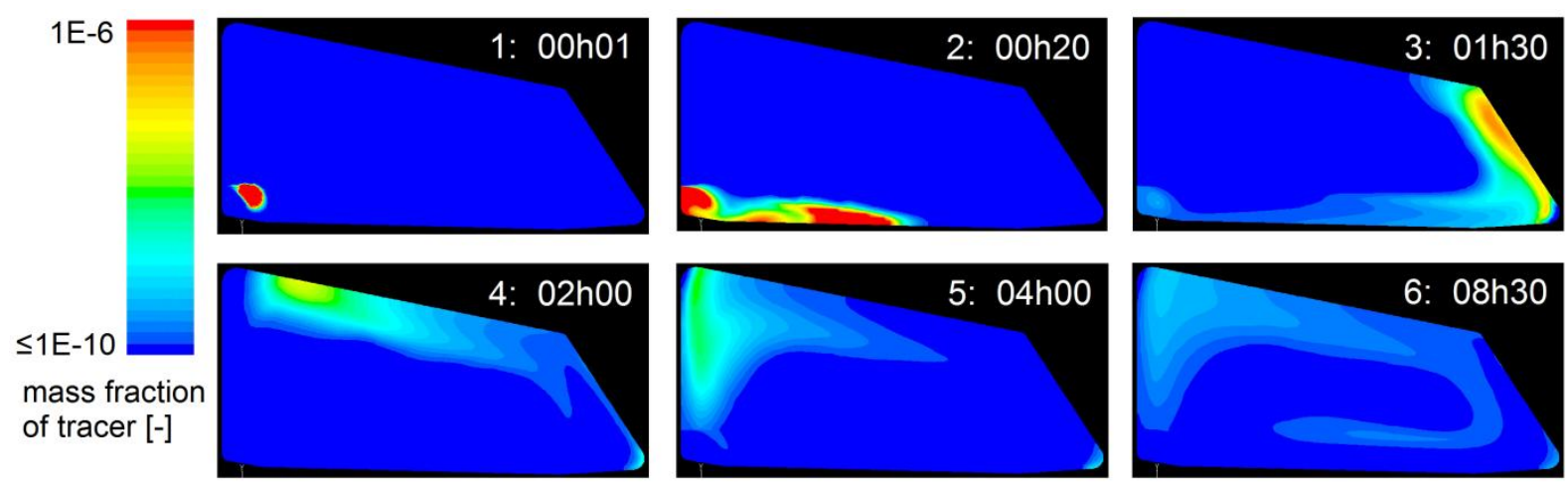

Figure 3. Sequential plots of the simulated transient tracer movement in pond M1. Colors at the top of the scale indicate higher tracer concentration.

Figure 3 shows the tracer movement in the pond at a depth of $0,01 \mathrm{~m}$ below surface by a sequence of photographs (from 1 to 6 ) depicting the vertical distribution of the mass fraction of the tracer. It is noticed in Figure 3 that the tracer reaches the outlet 90 minutes after the injection (photograph 3) following the dominant flow direction and confirming the short circuit in the pond; the first tracer loop around the pond is completed after 4 hours of injection (photograph 5); and, after completion of the second loop at 8,5 hours (photograph 6) the remainder of the tracer can be considered fully distributed in the pond domain. An eddy flow is noticed in the corner below the inlet 
(photographs 2 and 3) and a stagnant zone is observed in the bottom right corner of the pond (photographs 4, 5 and 6).

The computational resources needed for the CFD simulations were evaluated. Using an Intel Core i.5, 3,2 GHz processor, the CFD model of 75.000 grid elements needed an average of 20 hours of actual time of simulation to accomplish a run of 1 hour of simulation considering only flow and turbulence model equations. For the species transient simulation this time was reduced to 15 hours. The latter can be considered as reference for a full-scale pond system simulation in the absence of external boundary conditions.

\subsection{Tracer experiment vs. $C F D$}

Figure 4 shows a reasonable agreement between the RTD curves from the tracer study and the CFD model prediction. The CFD model was able to capture the magnitude and timing of the first peak reasonably well, but the subsequent peaks are less clear in the experimental results even though there seems to be one between $0,25 \mathrm{~d}$ and $0,50 \mathrm{~d}$. The disagreement could be due to the simplifying assumptions in the CFD model, e.g. the meteorological conditions were not included in the model analysis. Although the match is not perfect over the entire RTD curves, the validation results of the CFD model are fairly good. A fine-tuning of the model, incorporating some external factors could certainly improve the agreement; however, any further effort in this way should consider first the limitations and consequently the accurateness of the experimental data. On the basis of the match with the tracer results, the authors concluded that the CFD model quite appropriately simulates the hydraulics of the WSP.

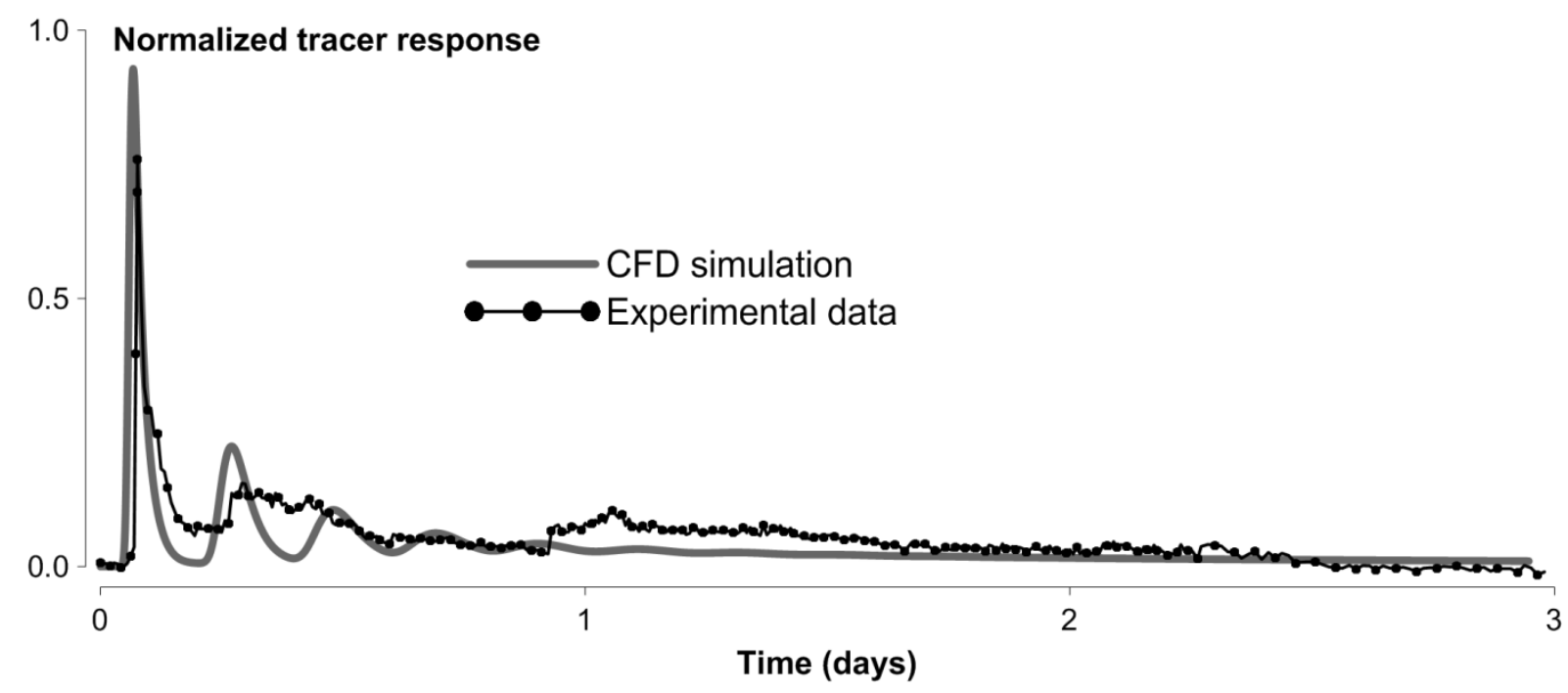

Figure 4. Comparison of the RTD curves obtained from the tracer experiment and the CFD model.

\subsection{Tracer experiment and CFD model RTD parameters analysis}

The parameters obtained in the RTD analysis in both tracer and CFD simulations are depicted in Table 1. The mean residence time and the variance show a significant difference in both approaches. The limitations of the experimental data and the assumptions made in the CFD simulations are most likely responsible for the differences, but open the possibility of fine-tuning. According to (Yanez, 1993) Eq. (9) is valid for flows largely deviating from plug-flows in the range of $0.02<\sigma_{\theta}^{2}<1$. For practical purposes, the lower limit in this range corresponds to systems behaving closer to a plug flow; and, for the higher limit, the system is closer to a complete mixing reactor. In this study the values for both approaches found for $\sigma_{\theta}^{2}$ were out of the range and consequently the dispersion factors could not be evaluated. As suggested by (Levenspiel, 1999) the statistical method described in Eq. (9) is then not appropriate for the systems under consideration. From the analysis it is clear that there are lots of 
independent random fluctuations and likely the hydraulic behavior in the pond is to a certain extent influenced by external factors. The latter suggests that in addition to tracer experiments, there is a need using tools able of describing more in detailed the hydraulics of the system accounting for: stagnant zones, recirculation zones and back-mixing flows. CFD modeling appears then as one of the most appropriate tools for this purposes.

Table 1. Parameters obtained from the RTD analysis.

\begin{tabular}{lcc}
\hline \multicolumn{1}{c}{ Parameter } & \multicolumn{2}{c}{ Approach } \\
& Tracer experiment & Modeling \\
\hline Mean residence time $(\bar{t})[$ day $]$ & 2.25 & 1.66 \\
Variance $\left(\sigma^{2}\right)\left[\right.$ day $\left.^{2}\right]$ & 4.73 & 4.51 \\
Dimensionless variance $\left(\sigma_{\theta}^{2}\right)[-]$ & 0.94 & 1.64 \\
\hline
\end{tabular}

\section{CONCLUSIONS}

Tracer experiments in large pond systems, although they are costly in terms of time and resources, are still very valuable to understand the system hydrodynamics. It is recommended taking the background fluorescence fluctuations in account when dealing with systems with high biomass concentrations. Rhodamine WT is an appropriate dye tracer since it is measurable at very low concentrations with inexpensive fluorometers.

The CFD model used in this study demonstrates its powerfulness and accurateness to describe the hydrodynamics of a large WSP, but at a high computational cost. Incorporation of external factors like wind and thermodynamic stratification can certainly improve the model but the computational demand will increase considerably. Although the amount of information obtained from CFD simulations is much appreciated for analysis, it is highly recommended to validate the model against experimental data for avoiding erroneous interpretation of results.

A properly description of full-scale waste stabilization ponds system should account for large backmixing, stagnant zones and random fluctuations (high turbulence in certain zones). The RTD curve from tracer experiments has certainly a limited analysis capacity with regard to the factors exposed above.

\section{ACKNOWLEDGEMENTS}

This work has been supported by a grant from the VLIR-UOS (Flemish Inter-University CouncelUniversity Development Cooperation) Program and ETAPA (Empresa Pública Municipal de Telecomunicaciones, Agua Potable, Alcantarillado y Saneamiento de Cuenca, Ecuador). The authors express their gratefulness to the students of the Faculty of Engineering of the Universidad de Cuenca and to Dr. Peter Aelterman, who collaborated in the tracer experiment campaigns. A special gratitude is expressed to Dr. Jan Feyen for having reviewed the manuscript.

\section{REFERENCES}

Dochain, D., S. Gregoire, A. Pauss, M. Schaegger, 2003. Dynamical modelling of a waste stabilisation pond. Bioprocess. Biosyst. Eng., 26, 19-26.

Domonte, M., D.D. Mara, 1987. The Hydraulic Performance of Waste Stabilizations Ponds in Portugal. Water Sci. Technol., 19, 219-227. 
Espinoza, E., P. Rengel, 2009. Evaluacion Hidraulica de la Planta de Tratamiento de Aguas Residuales de Ucubamba. Universidad de Cuenca, Engineering Faculty, Cuenca, Ecuador, 80 págs.

Karteris, A., A. Papadopoulos, G. Balafoutas, 2005. Modeling the temperature pattern of a covered anaerobic pond with computational fluid dynamics. Water Air Soil Pollut., 162, 107-125.

Levenspiel, O., 1999. Chemical Reaction Engineering, $3^{\text {rd }}$ Ed, Wiley \& Sons, NJ, USA.

Mara, D., G.P. Alabaster, H.W. Pearson, S.W. Mills, 1992. Waste Stabilization Ponds: A Design Manual for Eastern Africa. Lagoon Technology International, Leeds, England.

Moreno, M. D., 1990. A Tracer Study of the Hydraulics of Facultative Stabilization Ponds. Water Res., 24, 1025-1030.

Peterson, E.L., J.A. Harris, L.C. Wadhwa, 2000. CFD modelling pond dynamic processes. Aquacult. Eng., 23, 61-93.

Salter, H.E., C.T. Ta, S.C. Williams, 2000. Three-dimensional computational fluid dynamic modelling of a facultative lagoon. Water Sci. Technol., 42, 335-342.

Shilton, A., 2000. Potential application of computational fluid dynamics to pond design. Water Sci. Technol., 42, 327-334.

Shilton, A., J. Harrison, 2003. Integration of coliform decay within a CFD (computational fluid dynamic) model of a waste stabilisation pond. Water Sci. Technol., 48, 205-210.

Shilton, A., S. Kreegher, N. Grigg, 2008. Comparison of computation fluid dynamics simulation against tracer data from a scale model and full-sized waste stabilization pond. J. Environ. Eng., $134,845-850$.

Shilton, A., T. Wilks, J. Smyth, P. Bickers, 2000. Tracer studies on a New Zealand waste stabilisation pond and analysis of treatment efficiency. Water Sci. Technol., 42, 343-348.

Sweeney, D.G., J.B. Nixon, N.J. Cromar, H.J. Fallowfield, 2005. Profiling and modelling of thermal changes in a large waste stabilisation pond. Water Sci. Technol., 51, 163-172.

Sweeney, D.G., J.B. Nixon, N.J. Cromar, H. J. Fallowfield, 2007. Temporal and spatial variation of physical, biological, and chemical parameters in a large waste stabilisation pond, and the implications for WSP modelling. Water Sci. Technol., 55, 1-9.

Torres, J.J., A. Soler, J. Saez, L.M. Leal, M.I. Aguilar, 1999. Study of the internal hydrodynamics in three facultative ponds of two municipal WSPS in Spain. Water Res., 33, 1133-1140.

Torres, J.J., A. Soler, J. Saez, M. Llorens, 2000. Hydraulic performance of a deep stabilisation pond fed at 3.5 m depth. Water Res., 34, 1042-1049.

Torres, J. J., A. Soler, J. Saez, J.F. Ortuno, 1997. Hydraulic performance of a deep wastewater stabilization pond. Water Res., 31, 679-688.

Valero, M.A.C., D. Mara, 2009. The influence of algal biomass on tracer experiments in maturation ponds. Desalin. Water Treat., 4, 89-92.

Vedantam, S., J.B. Joshi, S.B. Koganti, 2006. CFD simulation of RTD and mixing in the annular region of a Taylor-Couette contactor. Ind. Eng. Chem. Res., 45, 6360-6367.

Vega, G.P., M.R. Pena, C. Ramirez, D.D. Mara, 2003. Application of CFD modelling to study the hydrodynamics of various anaerobic pond configurations. Water Sci. Technol., 48, 163-171.

Wood, M.G., P.F. Greenfield, T. Howes, M.R. Johns, J. Keller, 1995. Computational fluid dynamic modeling of waste-water ponds to improve design. Water Sci. Technol., 31, 111-118.

Wood, M.G., T. Howes, J. Keller, M.R. Johns, 1998. Two dimensional computational fluid dynamic models for waste stabilisation ponds. Water Res., 32, 958-963.

Yanez, F., 1986. Manual de Metodos Experimentales "Evaluacion de Lagunas de Estabilizacion". In: CEPIS (Ed.) Serie Tecnica 24. OPS-OMS, Lima, Peru, 181 págs.

Yanez, F., 1993. Lagunas de Estabilizacion - Teoria, Diseño, Evaluacion y Mantenimiento, ETAPA, Cuenca, Ecuador. 